\title{
Optimal control of heat pump water heater-instantaneous shower using integrated renewable-grid energy systems
}

\author{
Evan M. Wanjiru ${ }^{\mathrm{a}, *}$, Sam M. Sichilalu ${ }^{\mathrm{b}}$, Xiaohua Xia $^{\mathrm{a},}$ \\ ${ }^{a}$ Centre of New Energy Systems, Department of Electrical, Electronic and Computer Engineering, University of \\ Pretoria, Pretoria 0002, South Africa \\ ${ }^{b}$ Department of Electrical and Electronic Engineering, Faculty of Engineering, Mosi-O-Tunya University of Science \\ and Technology, Lusaka, Zambia
}

\begin{abstract}
Developing countries are grappling with energy and water insecurity, impelling governments to encourage end-users to conserve and efficiently consume these vital resources. With water heating being among the largest energy users in residential buildings, it is imperative that the efficiency and conservation of both energy and water are achieved. Heat pump water heaters (HPWHs) are a superior choice in efficiently providing domestic hot water. However, there are still challenges in their optimal operation and high initial cost in developing nations. Further, since they are normally centrally located in a house, there are water and associated energy losses during hot water conveyance to the end-use, as the cold water has to be poured away. This paper introduces an optimal control strategy of a hybrid HPWH and instantaneous shower powered using integrated renewable energy systems. This strategy has the potential to save $23.4 \%$ and $19 l$ of energy and water in a day respectively, while also promising lower energy and water bills to the end users. Further economic benefit can be achieved through the sale of excess renewable energy back to the grid through an appropriate feed-in tariff.
\end{abstract}

Keywords: Optimal control, Wind energy, Photovoltaic energy, grid energy, heat pump water heater, instantaneous shower

\begin{tabular}{|ll|}
\hline \multicolumn{2}{|l|}{ Nomenclature } \\
$A_{c}$ & area of photovoltaic (PV) array $\left(\mathrm{m}^{2}\right)$ \\
$A_{h p}, A_{i s}$ & surface area of HPWH's, instantaneous shower's storage $\left(\mathrm{m}^{2}\right)$ \\
$A_{w}$ & sweeping area of turbine rotor $\left(\mathrm{m}^{2}\right)$ \\
$C O P$ & coefficient of performance \\
$C_{p}$ & power coefficient of wind turbine \\
$c_{w}$ & specific heat capacity of water $\left(\mathrm{J} / \mathrm{kg}^{\circ} \mathrm{C}\right)$ \\
\hline
\end{tabular}

The short version of the paper was presented at REM2016 on April 19-21, Maldives. This paper is a substantial extension of the short version.

*Corresponding author. Tel. +27 12420 6767; Fax +27 123625000 .

Email address: murimev@gmail . com (Evan M. Wanjiru ) 


\begin{tabular}{|c|c|}
\hline$D_{t o t}, D_{i s}$ & HPWH, instantaneous shower water demand $(\mathrm{kg} / \mathrm{h})$ \\
\hline$\Delta x$ & thickness of insulation material $(m)$ \\
\hline$h$ & coefficient of surface heat transfer $\left(\mathrm{W} / \mathrm{m}^{2} \mathrm{~K}\right)$ \\
\hline$\eta_{g}, \eta_{t}$ & generator, gearbox efficiency \\
\hline$\eta_{i s}$ & efficiency of instantaneous shower's heating element \\
\hline$\eta_{p v}$ & efficiency of photovoltaic generator \\
\hline$I_{p v}$ & solar irradiation on photovoltaic array $\left(\mathrm{kWh} / \mathrm{m}^{2}\right)$ \\
\hline$J$ & objective function \\
\hline$k$ & coefficient of thermal conductivity $(\mathrm{W} / \mathrm{mK})$ \\
\hline$m_{h p}, m_{i s}$ & mass of water inside $\mathrm{HPWH}$, instantaneous shower $(\mathrm{kg})$ \\
\hline$N$ & total number of samples during the $24-\mathrm{h}$ operating cycle \\
\hline$\rho_{a}$ & density of air $\left(\mathrm{kg} / \mathrm{m}^{3}\right)$ \\
\hline$p_{e}$ & price of electricity using TOU tariff (currency/ $k W h$ ) \\
\hline$P_{g}$ & grid power $(k W)$ \\
\hline$P_{h p}, P_{i s}$ & power rating of $\mathrm{HPWH}$, instantaneous shower $(\mathrm{kW})$ \\
\hline$P_{l}$ & domestic load $(k W)$ \\
\hline$p_{o f f}, p_{\text {peak }}$ & off-peak, peak electricity price in the TOU tariff (currency/kWh) \\
\hline$P_{p v}, P_{w}$ & photovoltaic, wind power $(k W)$ \\
\hline$Q_{d}, Q_{l}$ & thermal power loss due to water flow, standby losses $(W)$ \\
\hline$R_{h p}, R_{i s}$ & thermal resistance of insulating material $\left(\mathrm{m}^{2} \mathrm{~K} / \mathrm{W}\right)$ \\
\hline TOU & time-of-use tariff \\
\hline$T_{a}$ & ambient temperature $\left({ }^{\circ} \mathrm{C}\right)$ \\
\hline$T_{h p}, T_{i s}$ & temperature of water inside $\mathrm{HPWH}$, instantaneous shower $\left({ }^{\circ} \mathrm{C}\right)$ \\
\hline$T_{h p}^{i n}, T_{i s}^{i n}$ & temperature of incoming water to HPWH, instantaneous shower $\left({ }^{\circ} \mathrm{C}\right)$ \\
\hline$t_{s}$ and $j$ & sampling period $(h)$ and $j^{t h}$ sampling interval \\
\hline$u_{h p}, u_{i s}$ & status of HPWH's, instantaneous shower's switch \\
\hline$V_{c}, V_{i}, V_{N}$ & cut out, cut in, rated wind speed $(\mathrm{m} / \mathrm{s})$ \\
\hline$\omega$ & weighting factor \\
\hline $\operatorname{Rand}(\mathrm{R})$ & South African currency (( 1 Rand $=0.074$ USD $)$, as at 17 Aug. 2016) \\
\hline
\end{tabular}

\section{Introduction}

Renewable energy is increasingly being adopted by many countries in the world with the aim of reducing over-reliance on fossil fuels. However, remote areas in many developing nations, such as Africa and most islands developing nations are not connected to the grid. They are therefore relying on fossil fuel generators despite their high potential for renewable energy [1]. The negative environmental effect of fossil fuels, coupled with high fuel importation transport cost and diseconomies of scale in electricity production lead to exorbitantly high energy cost and long term financial risks for the economy [2]. Furthermore, increasing population is straining the existing energy infrastructure through increasing energy demand. By 2020, energy use by developing nations will grow at an average annual rate of 3.2\% surpassing $1.1 \%$ in the developed countries [3]. 
Renewable energy technologies are a sustainable solution to providing cheaper and cleaner energy in these areas. For instance, in Maldives islands, hybrid solar and wind electricity generation systems have been proven to be financially feasible for supplementing the fossil fuel based grid [4]. Adoption of these hybrid renewable energy systems is faced with the challenge of designing an optimal energy management system that satisfies the load while considering the intermittent nature of renewable energy sources and variations in power demand [5].

Domestic water heating is the fourth largest energy user in commercial buildings, after heating, air conditioning, and lighting, and third largest in residential buildings [6]. Studies from various parts of the world reveal that domestic water heating, when compared with total energy consumption in buildings, is responsible for 18\% in the USA [7], 25\% in UK [8], 26\% in Spain [3], 30\% in Australia [9] and 20\% in Brazil [10]. This has led to increased effort in improving energy efficiency of domestic hot water systems, whose level determines the energy saving potential [11]. Heat pumps offer economically attractive choices as they recoup heat from various industrial, commercial and residential applications [12]. Heat pump water heaters (HPWHs) operate on the principle of the refrigerant cycle converting one unit of electrical energy to produce three units of thermal energy [13]. Despite the superiority, improvement of its performance, reliability, and environmental impact have been a concern [12], while optimal operation and integration of the technologies remains a challenge [14]. These challenges, coupled with high initial investment cost especially in developing countries have hindered their uptake. For instance, in South Africa the market penetration of HPWH is $16 \%$ [15].

Various studies have looked at ways to achieve energy efficiency using HPWHs. Kreuder and Spataru [16] showed that heat pumps can indeed be used to enhance energy efficiency in homes while Aste et al. [17] showed their economic feasibility. Further, various control algorithms have shown their potential in reducing the delivered energy and its cost but predictive control algorithm was the most effective [18]. Integration of distributed renewable energy provides a huge potential in powering HPWHs further increasing the energy savings [19]. Therefore, an optimal control model of a grid tied photovoltaic (PV) and diesel generator integrated system applicable in areas with intermittent power supply was used to power HPWHs [14]. In another study, an optimal power dispatch model of a grid tied photovoltaic system was used to power HPWH. The model showed energy savings potential and ability to use the stored energy in the battery in case of power black out, or during peak time [20]. An optimal controller for the HPWH powered using integrated wind generator-photovoltaic-grid system led to energy savings further improving the energy efficiency of the HPWH while feeding back excess power back to the grid through a suitable feed-in tariff [21]. This study was advanced by incorporating a fuel cell which improved the reliability of the intermittent renewable power supplies. The optimal control strategy showed the possibility of integrating renewable energy systems and energy efficient systems [22]. Despite the superiority of HPWHs to other water heating technologies, they have a slow rate of heating water. Consequently, in cases with high demand for hot water, HPWHs are unable to supply it. Further, since HPWHs are normally centrally located in the house, energy and water losses associated with the hot water conveyance to the consumption point occur as the cold water in the pipe is wasted while waiting for hot water at the point of use. Upon finishing with the use, the remaining water in the pipe quickly cools down [23]. To address these challenges, instantaneous water heaters, placed at the consumption point, can be used [24]. Although previous studies have 
mainly concentrated on energy demand management, the demand management of energy-water nexus gaining more attention in developing nations [25], with instantaneous heaters proposed as a suitable option [26].

This paper introduces a novel and economical optimal control strategy that ensures both energy and water are efficiently consumed by using HPWH and instantaneous shower to conveniently meet domestic hot water demand. The shower end use is selected in this study as it is one of the most hot water intensive end uses in homes. The control model uses integrated wind-photovoltaic renewable energy to power the hot water devices, needing grid power whenever they are insufficient. However, whenever renewable energy is in excess, it is sold back to the grid through an appropriate feed-in tariff. Therefore, the aim of the controls is to optimally operate both hot water devices, maximizing the use of renewable energy effectively ensuring the customer incurs the least cost of electricity. The controls further minimize water loss during conveyance to the shower.

\section{Controller formulation}

\subsection{Schematic layout}

Figure 1 shows the schematic diagram of the water heating system comprising of the HPWH and the instantaneous shower. The water heating devices are powered using photovoltaic solar, $P_{p v}$, and wind generator, $P_{w}$, while grid, $P_{g}$, acts as a back whenever the renewable sources are insufficient. The HPWH, centrally located in the house, meets the total hot water demand. The instantaneous shower is placed in the shower to act as back up whenever the water from the HPWH is not at the required temperature. Switches $u_{h p}$ and $u_{i s}$ control the power flow to HPWH and instantaneous shower respectively. The grid supplements power from the renewable sources as well as accepting excess power back.

\subsection{Wind energy}

Wind energy is one of the integrated renewable energy system used to power the hot water devices. Whenever there is excess wind energy than that required by the hot water devices, it is fed back to the grid using an appropriate feed-in tariff. The power output of a typical wind turbine is proportional to the cubed wind speed as long as this speed is between the cut in wind speed, $V_{i}$ and rated wind speed, $V_{N}$. For a simplified model of a wind generator, the power output, $P_{w}$, at the rated wind speed is [27],

$$
P_{w}=0.5 \eta_{t} \eta_{g} \rho_{a} C_{p} A_{w} V_{r}^{3}
$$

where $\eta_{t}$ and $\eta_{g}$ are the gearbox and generator efficiency respectively. $\rho_{a}$ is the density of air $\left(\mathrm{kg} / \mathrm{m}^{3}\right), C_{p}$ is the power coefficient of the turbine, $A_{w}$ is the sweeping area of the turbine rotor $\left(\mathrm{m}^{2}\right)$ while $V_{r}$ is the speed of wind $(\mathrm{m} / \mathrm{s})$. Whenever the wind speed is above $V_{N}$, the aerodynamic efficiency is reduced by pitching the blades so that shaft power remains constant. However, if the wind speed exceeds the pitch control limit, it reaches the cut-out wind speed, $V_{c}$, and power production is stopped [28]. 


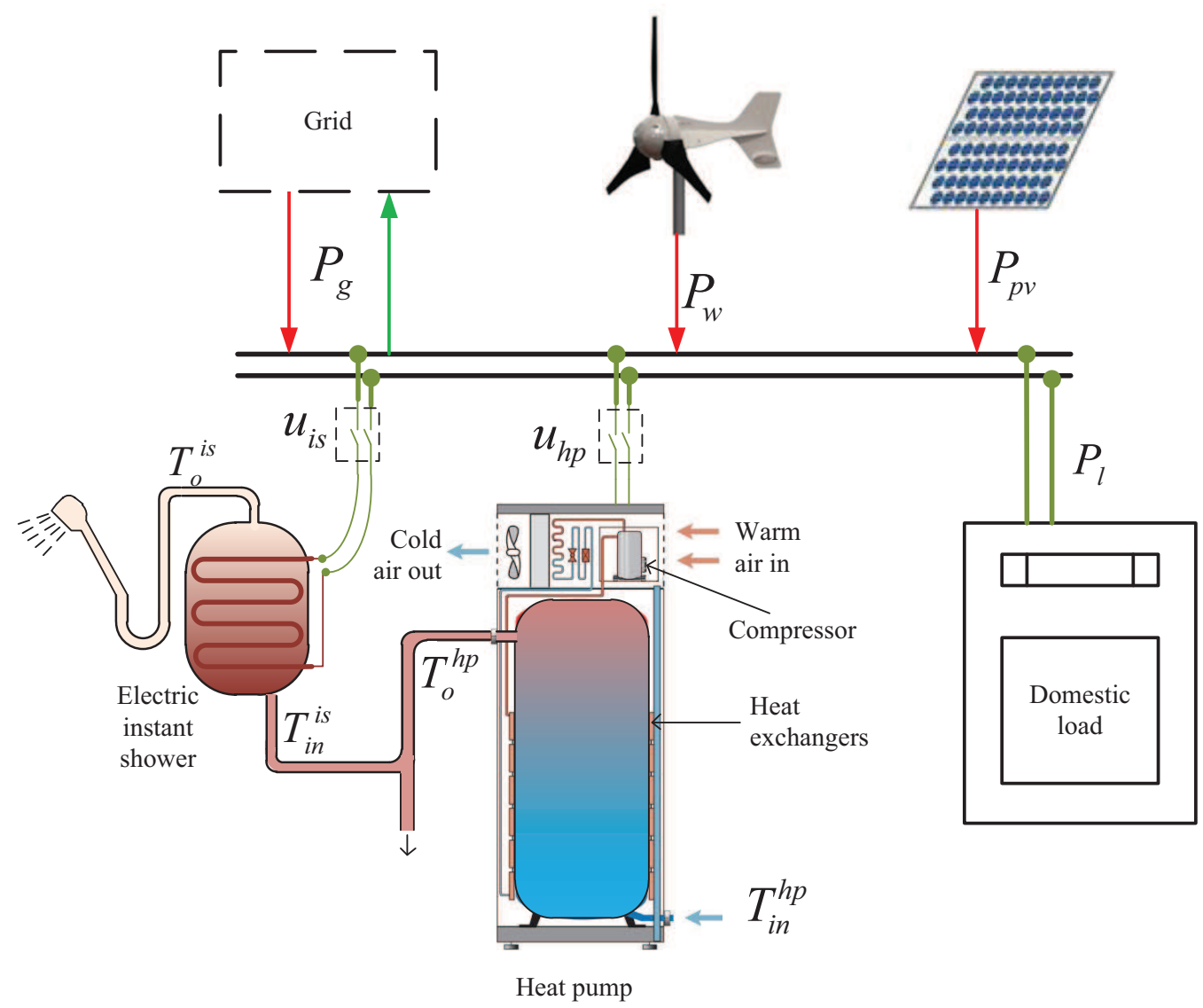

Figure 1: Schematic layout of the energy and hot water flow

\subsection{Photovoltaic solar energy}

A solar cell is the basic component used to directly transform sunlight into electricity. The series connection of several of these cells form a module while series-parallel connection of modules form an array [29]. The power generated by a PV array is given as,

$$
P_{p v}=\eta_{p v} A_{c} I_{p v}
$$

where $A_{c}$ is the area of the PV array, $I_{p v}$ is the solar irradiation incident on the PV array $\left(\mathrm{kWh} / \mathrm{m}^{2}\right)$ while $\eta_{p v}$ is the efficiency of the PV generator, which is dependent on $I_{p v}$ and ambient temperature, $T_{A}$, [30]. The solar irradiation varies depending on the time of the day such that,

$$
I_{p v}=R_{B}\left(I_{B}+I_{D}\right)+I_{D}
$$

where $R_{B}$ is a geometric factor representing the ratio of beam irradiance incident on a tilted plane to that incident on a horizontal plane. $I_{B}$ and $I_{D}$ are the hourly global and diffuse irradiation $\left(\mathrm{kWh} / \mathrm{m}^{2}\right)$ respectively, [31]. The PV array is also a part of the integrated renewable energy system supplying power to the hot water devices. Just like the case of wind power, excess PV power is also sold back to the grid. 


\subsection{Grid energy}

The grid is modelled as an infinite bar capable of supplying power to hot water devices whenever renewable energy is insuffient. It is also capable of accepting excess renewable power to meet other energy demands within its network. In supply mode, the grid electricity's price is structured as a time-of-use (TOU) tariff. In this study, Eskom's TOU Homeflex structure is used [32], The hourly price of electricity, $p_{e}(t)$, being,

$$
p_{e}(t)=\left\{\begin{array}{llll}
p_{\text {off }}=0.5510 & R / K w h & \text { if } t \in[0,6] \cup[10,18] \cup[20,24] \\
p_{\text {peak }}=1.7487 & R / K w h & \text { if } t \in[7,10] \cup[18,20]
\end{array}\right.
$$

where $p_{\text {off }}$ is the off peak price, $p_{\text {peak }}$ is the peak price, $R$ is the South African currency, Rand, and $t$ is the time of day in hours. The tariff has five charge components as service charge, network charge, environmental levy, peak charge and off-peak charges [33]. The National Energy Regulator of South Africa (NERSA) revised the renewable energy feed in tariff (REFIT) in 2013 with the prevailing REFIT for wind and solar photovoltaic being $1.25 R / k W h$ and $3.94 R / k W h$ respectively [34].

The hourly power balance for meeting the demand of the hot water devices is modelled as,

$$
P_{h p} u_{h p}(t)+P_{i s} u_{i s}(t)+P_{l}(t)=P_{g}(t)+P_{w}(t)+P_{p v}(t) .
$$

where $P_{h p}$ and $P_{i s}$ are the power rating $(k W)$ of the heat pump and instantaneous shower respectively, whose on/off status are represented as $u_{h p}(t)$ and $u_{i s}(t)$ respectively. $P_{l}(t)$ is the hourly power $(k W)$ demand from other domestic load.

\subsection{Heat pump water heater}

A HPWH is generally composed of heat pumping and hot water reservoir parts. Although mechanical and thermal inertia are important in modelling the heat pumping part, HPWHs take much shorter time in stabilizing from mechanical inertia than thermal inertia. This means that the suction and discharge conditions of the heat pump can be used to model the steady state characteristics of the HPWH if the compressor operates in a constant speed condition [35]. The hot water reservoir stores the hot water heated upon being forced to circulate through the condenser absorbing the heat [36]. Whenever hot water flows from the reservoir to meet the demand, the reservoir is re-filled with cold water. In order to simplify the model, energy losses in the evaporator, refrigerant and compressor are neglected. However, the overall efficiency the thermal components are accounted for by the coefficient of performance (COP) obtained in the case study. It is also assumed that the temperature of water throughout the reservoir is uniform. Hence, energy losses considered in this model are standby losses and losses associated to the hot water demand.

Standby power losses $\left(Q_{l}\right)$ are thermal losses to the environment due to heat conduction through the surface of the tank and natural convection that transfers heat from the surface of the tank to the environment. These losses can be reduced through the use of improved thermal insulated material [37]. Standby losses are modelled as,

$$
Q_{l}=A_{h p}\left(\frac{T_{h p}-T_{a}}{R_{h p}}\right)
$$


where $A_{h p}$ is the surface area of the HPWH's tank $\left(m^{2}\right)$ while $T_{h p}$ and $T_{a}$ are the hot water and ambient temperatures respectively $\left({ }^{\circ} \mathrm{C}\right) . R_{h p}$ is the thermal resistance of the insulation material $\left(m^{2} K / W\right)$, which can be written as,

$$
R=\frac{\Delta x}{k}+\frac{1}{h}
$$

where $\Delta x$ is the thickness of the insulation material $(m)$ while $k$ and $h$ are the coefficients of thermal conductivity $(W / m k)$ and surface heat transfer $\left(W / m^{2} k\right)$ respectively [38].

Hot water demand causes hot water to flow out of the tank which is consequently replaced by the same volume of cold water [39]. This flow of water in and out of the tank causes a drop in the average temperature, $T_{h p}$, of the hot water in the tank [40]. Thermal power losses due to water flow, $Q_{d}$, can be modelled as,

$$
Q_{d}=c_{w} D_{t o t}\left(T_{h p}-T_{h p}^{i n}\right),
$$

where $c_{w}$ is the specific heat capacity of water $\left(\mathrm{J} /\left(\mathrm{kg} .{ }^{\circ} \mathrm{C}\right)\right) . T_{h p}^{i n}$ is the temperature of the cold water into the tank $\left({ }^{\circ} \mathrm{C}\right)$ and $D_{t o t}$ is the total hot water demand, given as the mass flow rate of hot water $(\mathrm{kg} / \mathrm{h})$.

The electrical power required from the HPWH, $Q_{h}$, to maintain water at the required temperature while overcoming the above losses is [41],

$$
Q_{h}=C O P \times P_{h p}
$$

where $C O P$ is the coefficient of performance. In meeting the hot water demand, the dynamic model of HPWH is based on the open energy balance [42]. The resulting differential equation describing the average thermal response of water in the tank is [43],

$$
c_{w} m_{h p} \frac{d T_{h p}}{d t}=Q_{h}-Q_{l}-Q_{d}
$$

where $m_{h p}$ is the mass of water $(\mathrm{kg})$ in HPWH's storage tank. By substituting for $Q_{h}, Q_{l}$ and $Q_{d}$, equation 10 now becomes,

$$
c_{w} m_{h p} \frac{d T_{h p}}{d t}=(C O P) P_{h p} u_{h p}(t)-A_{h p}\left(\frac{T_{h p}(t)-T_{a}}{R}\right)-c_{w} D_{t o t}(t)\left(T_{h p}(t)-T_{h p}^{i n}(t)\right)
$$

In order to simplify the modelling process, the above differential equation can be written as

$$
\frac{d T_{h p}}{d t}=-\alpha(t) T_{h p}(t)+\beta u_{h p}(t)+\gamma(t),
$$

where

$$
\begin{gathered}
\alpha(t)=\frac{A_{h p}}{c_{w} m_{h p} R}+\frac{D_{t o t}(t)}{m_{h p}}, \\
\beta=\frac{(C O P) P_{h p}}{c_{w} m_{h p}}, \\
\gamma(t)=\frac{A_{h p} T_{a}}{c_{w} m_{h p} R}+\frac{D_{t o t}(t) T_{h p}^{i n}(t)}{m_{h p}} .
\end{gathered}
$$


Differential equation (12) can be expressed in discrete-time domain such that the temperature of water in HPWH's storage at $j^{\text {th }}$ sampling interval becomes,

$$
T_{h p}(j+1)=\left(1-t_{s} \alpha(j)\right) T_{h p}(j)+t_{s} \beta u_{h p}(j)+t_{s} \gamma(j)
$$

where $t_{s}$ is the sampling period $(h)$. The status of the HPWH's switch, $u_{h p}(j)$, is such that,

$$
u_{h p}(j) \in\{0,1\} \quad 1 \leq j \leq N,
$$

where $N$ is the total number of samples in a 24-h operating cycle such that $N=\frac{24}{t_{s}}$. Through recurrence manipulation, equation (14) can be expressed in terms of the initial temperature, $T_{h p}(0)$, as,

$$
\begin{gathered}
T_{h p}(j)=T_{h p}(0) \prod_{i=1}^{j}\left(1-t_{s} \alpha(i)\right)+\beta t_{s} \sum_{i=1}^{j} u_{h p}(i) \prod_{k=i+1}^{j}\left(1-t_{s} \alpha(k)\right)+t_{s} \sum_{i=1}^{j} \gamma(i) \prod_{k=i+1}^{j}\left(1-t_{s} \alpha(k)\right) \\
1 \leq j \leq N .
\end{gathered}
$$

\subsection{Instantaneous shower}

Instantaneous water heaters, also called demand or tank-less water heaters, have heating elements that are activated by the flow of water thereby heating the water instantly as it passes through [44]. By virtue of heating water on demand, they require larger power input than the storage water heaters [45]. They are either electric, gas or propane powered [46], though this paper focuses on electric powered instantaneous showers. Central storage water heaters lead to energy and water wastage in supplying remote end-uses such as shower. The tap has to run until hot water arrives and the remaining hot water in the pipe after the tap is closed becomes cold quickly. In such a case, instantaneous shower would improve the efficiency of these resources by nearly eliminating distribution and standby losses. They also offer a perfect candidate to support central storage hot water systems that cannot conveninently meet the hot water demand such as central solar tanks and HPWHs [24]. The instantaneous shower is modelled in two states;

\subsubsection{Active state}

Whenever there is demand for shower water, hot water from the HPWH is flowing. In this model, we assume there is negligible heat loss as the water flows along the pipes to the instantaneous shower. Similar to the HPWH, the energy balance of the instantaneous shower in active state can be represented by a first order differential equation as,

$$
c_{w} m_{i s} \frac{d T_{i s}}{d t}=\eta_{i s} P_{i s} u_{i s}(t)-A_{i s}\left(\frac{T_{i s}(t)-T_{a}}{R_{i s}}\right)-c_{w} D_{i s}(t)\left(T_{i s}(t)-T_{i s}^{i n}(t)\right)
$$

where $m_{i s}$ is the mass of water inside the instantaneous shower's chamber $(\mathrm{kg}), \eta_{i s}$ is the efficiency of the heating element rated at $P_{i s}$ in $k W . A_{i s}$ is the surface area of the instantaneous shower while $R_{i s}$ is the thermal resistance of the shower's material and $T_{i s}^{i n}$ is the temperature of water $\left({ }^{\circ} \mathrm{C}\right)$ into the instantaneous shower. $u_{i s}(t)$ is the state of the instantaneous shower's switch at time, $t$, while $D_{i s}(t)$ is the hot water demand in the shower $(\mathrm{kg} / \mathrm{hr})$. Just like in equation (11), the second and 
third terms of the right hand side of equation (17) represent the standby and water usage thermal losses respectively [47]. Differential equation (17) can be simplified to,

$$
\frac{d T_{i s}}{d t}=-\phi(t) T_{i s}(t)+\lambda u_{i s}(t)+\zeta(t)
$$

where

$$
\begin{gathered}
\phi(t)=\frac{A_{i s}}{c_{w} m_{i s} R_{i s}}+\frac{D_{i s}(t)}{m_{i s}}, \\
\lambda=\frac{\eta P_{i s}}{c_{w} m_{i s}}, \\
\zeta(t)=\frac{A_{i s} T_{a}}{c_{w} m_{i s} R_{i s}}+\frac{D_{i s}(t) T_{i s}^{i n}(t)}{m_{i s}} .
\end{gathered}
$$

Discretizing equation (18) yields,

$$
T_{i s}(j+1)=\left(1-t_{s} \phi(j)\right) T_{i s}(j)+t_{s} \lambda u_{i s}(j)+t_{s} \zeta(j)
$$

where the status of the instantaneous shower's switch, $u_{i s}(j)$, is such that,

$$
u_{i s}(j) \in\{0,1\} \quad 1 \leq j \leq N,
$$

Expressing equation (20) in terms of the initial temperature, $T_{i s}(0)$, of water in the instantaneous shower becomes,

$$
\begin{aligned}
& T_{i s}(j)=T_{i s}(0) \prod_{i=1}^{j}\left(1-t_{s} \phi(i)\right)+\lambda t_{s} \sum_{i=1}^{j} u_{i s}(i) \prod_{k=i+1}^{j}\left(1-t_{s} \phi(k)\right)+t_{s} \sum_{i=1}^{j} \zeta(i) \prod_{k=i+1}^{j}\left(1-t_{s} \phi(k)\right) \\
& 1 \leq j \leq N \text {. }
\end{aligned}
$$

\subsubsection{Idle state}

The idle state occurs whenever the instantaneous shower is not in use. Unlike the HPWH that takes the inlet water at the ambient temperature, the water into the instantaneous shower is already heated by the HPWH. However, in the idle state, there is no demand for the shower implying that the water is stagnant in the pipes between HPWH and instantaneous shower as well as in the instantaneous shower's small reservoir. Assuming that the water in the pipe is losing heat at the same rate as that in the instantaeous shower, the differential equation governing the behaviour of water in the instantaneous shower can be modelled as [48],

$$
c_{w} m_{i s} \frac{d T_{i s}}{d t}+A_{i s}\left(\frac{T_{i s}(t)-T_{a}}{R_{i s}}\right)=0
$$




\subsection{Optimization problem}

The aim of the controller is to minimize the cost of grid power consumed as well the use of instantaneous shower in meeting the hot water demand. In this paper, we consider an evaluation period of a 24-h operating cycle from 0 to hour 24 with a sampling period $t_{s}=15 \mathrm{~min}$. The objective function, $J$, can therefore be expressed as,

$$
J=\omega \sum_{j=1}^{N} t_{s} p_{e}(j) P_{g}(j)+(1-\omega) \sum_{j=1}^{N} t_{s} P_{i s} u_{i s}(j)
$$

where $\omega$ is a weighting factor chosen to indicate the relative importance of minimizing each term in the objective function [49]. The first term seeks to minimize the cost of grid power consumed by the hot water devices while the second term minimizes the use of instantaneous shower. The objective function is subject to the following technical and operational constraints,

$$
\begin{array}{r}
P_{w}(j)+p_{g}(j)+P_{p v}(j)=P_{h p} u_{h p}(j)+P_{i s} u_{i s}(j)+P_{l}(j), \\
T_{h p}^{\min } \leq T_{h p}(j) \leq T^{\max }, \\
T_{i s}^{\min } \leq T_{i s}(j) \leq T^{\max }, \\
-\infty \leq P_{g}(j) \leq \infty, \\
u_{h p}(j) \in\{0,1\}, \\
u_{i s}(j) \in\{0,1\},
\end{array}
$$

where $T_{h p}^{\min }$ and $T_{i s}^{\min }$ are the minimum allowable temperature $\left({ }^{\circ} \mathrm{C}\right)$ of the HPWH and the instantaneous shower respectively, while $T^{\max }$ is the maximum temperature $\left({ }^{\circ} \mathrm{C}\right)$ which is the same for both devices. Equality constraint (25) represents the power balance in the system, whereby, power from renewable energy sources and grid are used to meet power demand from hot water devices as well as domestic load at every sampling interval, $j$. Constraints (26) and (27) show the state variables, that is, temperature of water from HPWH and instantaneous shower respectively, must be between set minimum and maximum acceptable temperature in every sampling interval, $j$. Constraints (28)-(30) show how control variables are bound. Grid power, $P_{g}$, is bound such that, even though it provides power, it can also accept power back from the renewable sources. Finally, the status of the HPWH and instantaneous shower switches can take the values of either 0 or 1 representing off and on status respectively.

\subsubsection{Algorithm}

Objective function (24) is solved using the canonical form [50].

$$
\min f^{T} X
$$

subject to

$$
\left\{\begin{array}{l}
A X \leq b \text { (linear inequality constraint), } \\
A_{e q} X=b_{e q} \text { (linear equality constraint), } \\
L_{B} \leq X \leq U_{B} \text { (lower and upper bounds). }
\end{array}\right.
$$


Vector $X$ contains all control variables such that,

$$
X=\left[\begin{array}{lllllllll}
u_{h p}(1) & \ldots & u_{h p}(N) & u_{i s}(1) & \ldots & u_{i s}(N) & P_{g}(1) & \ldots & P_{g}(N)
\end{array}\right]_{3 N \times 1}^{T},
$$

meaning

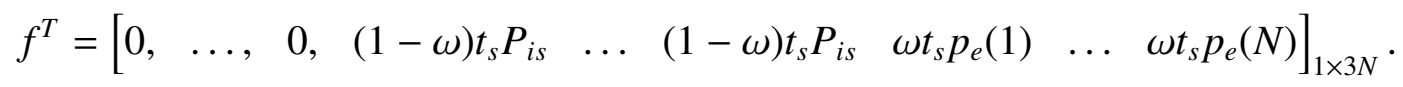

From the power balance equality constraint $(28)$, matrix $A_{e q}$ becomes,

$$
A_{e q}=\left[\begin{array}{cccc:cccc:cccc}
P_{h p} & 0 & \ldots & 0 & P_{i s} & 0 & \ldots & 0 & -1 & 0 & \ldots & 0 \\
0 & P_{h p} & \ldots & 0 & 0 & P_{i s} & \ldots & 0 & 0 & -1 & \ldots & 0 \\
\vdots & \vdots & \ddots & \vdots & \vdots & \vdots & \ddots & \vdots & \vdots & \vdots & \ddots & \vdots \\
0 & 0 & \ldots & P_{h p} & 0 & 0 & \ldots & P_{i s} & 0 & 0 & \ldots & -1
\end{array}\right]_{N \times 3 N}
$$

and vector $b_{e q}$,

$$
b_{e q}=\left[\begin{array}{c}
P_{w}(1)+P_{p v}(1)-P_{l}(1) \\
\vdots \\
P_{w}(N)+P_{p v}(N)-P_{l}(N)
\end{array}\right]_{N \times 1} .
$$

The temperature of hot water from HPWH modelled in inequality constraint 26] can be written as,

$$
\begin{aligned}
A_{1} X & \leq b_{1}, \\
-A_{1} X & \leq b_{2} .
\end{aligned}
$$

By letting $\left(\sigma(j)=1-t_{s} \alpha(j)\right)$, matrix $A_{1}$, with a dimension of $(N \times 3 N)$ is,

$$
A_{1}=-\beta t_{s} \times
$$

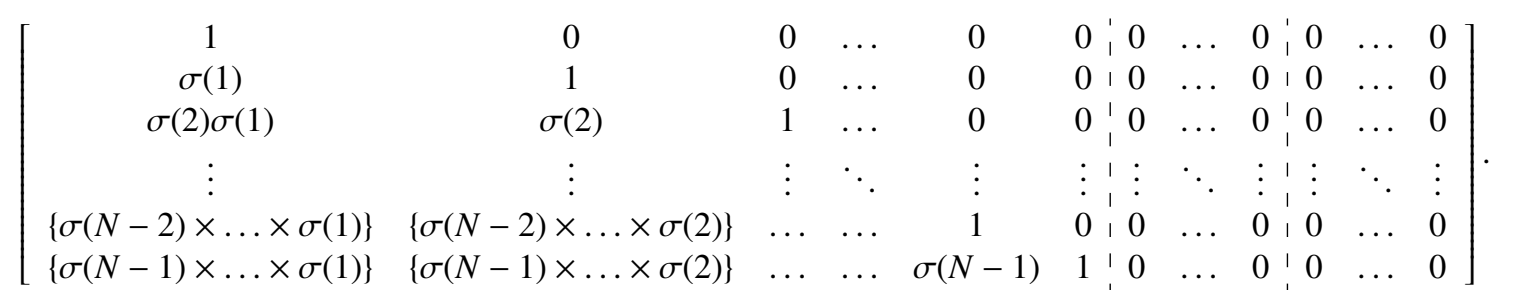

Further, vector $b_{1}(N \times 1)$ can be written as,

$$
b_{1}=-b_{1,1}+b_{1,2}+b_{1,3}
$$

where,

$$
\begin{gathered}
b_{1,1}=\left[\begin{array}{ccc}
T_{h p}^{\min } & \ldots & T_{h p}^{\min }
\end{array}\right]_{N \times 1}^{T}, \\
b_{1,2}=T_{h p}(0)\left[\begin{array}{c}
\sigma(1) \\
\sigma(2) \sigma(1) \\
\sigma(3) \sigma(2) \sigma(1) \\
\vdots \\
\sigma(N) \sigma(N-1) \ldots \sigma(1)
\end{array}\right]_{N \times 1},
\end{gathered}
$$


and

$$
b_{1,3}=t_{s}\left[\begin{array}{c}
\gamma(1) \\
\sigma(2) \gamma(1)+\gamma(2) \\
\sigma(3) \sigma(2) \gamma(1)+\sigma(3) \gamma(2)+\gamma(3) \\
\vdots \\
\{\sigma(N) \sigma(N-1) \ldots \sigma(2)\} \gamma(1)+\ldots+\sigma(N-2) \gamma(N-1)+\gamma(N)
\end{array}\right]_{N \times 1}
$$

while vector $b_{2}(N \times 1)$ becomes,

$$
b_{2}=b_{2,1}-b_{1,2}-b_{1,3}
$$

where,

$$
b_{2,1}=\left[\begin{array}{lll}
T_{\max } & \ldots & T_{\max }
\end{array}\right]_{N \times 1}^{T} .
$$

Similarly the temperature of hot water from the instantaneous shower in inequality (27) becomes,

$$
\begin{aligned}
A_{2} X & \leq b_{3}, \\
-A_{2} X & \leq b_{4} .
\end{aligned}
$$

By letting $\left(\psi=1-t_{s} \phi(j)\right)$, matrix $A_{2}(N \times 3 N)$ becomes,

$$
\begin{aligned}
& A_{2}=-\lambda t_{s} \times \\
& {\left[\begin{array}{ccc:cccccc:ccc}
0 & \ldots & 0 & 1 & 0 & 0 & \ldots & 0 & 0 & 0 & \ldots & 0 \\
0 & \ldots & 0 & \psi(1) & 1 & 0 & \ldots & 0 & 0 & 0 & \ldots & 0 \\
0 & \ldots & 0 & \psi(2) \psi(1) & \psi(2) & 1 & \ldots & 0 & 0 & 0 & \ldots & 0 \\
\vdots & \ddots & \vdots & \vdots & \vdots & \vdots & \ddots & \vdots & \vdots & \vdots & \ddots & \vdots \\
0 & \ldots & 0 & \{\psi(N-2) \times \ldots \times \psi(1)\} & \{\psi(N-2) \times \ldots \times \psi(2)\} & \ldots & \ldots & 1 & 0 & 0 & \ldots & 0 \\
0 & \ldots & 0 & \{\psi(N-1) \times \ldots \times \psi(1)\} & \{\psi(N-1) \times \ldots \times \psi(2)\} & \ldots & \ldots & \psi(N-1) & 1 & 0 & \ldots & 0
\end{array}\right] .}
\end{aligned}
$$

Vector $b_{3}(N \times 1)$ now becomes,

$$
b_{3}=-b_{3,1}+b_{3,2}+b_{3,3}
$$

where,

$$
\begin{gathered}
b_{3,1}=\left[\begin{array}{lll}
T_{i s}^{\min } & \ldots & T_{i s}^{\min }
\end{array}\right]_{N \times 1}^{T}, \\
b_{3,2}=T_{i s}(0)\left[\begin{array}{c}
\psi(1) \\
\psi(2) \psi(1) \\
\psi(3) \psi(2) \psi(1) \\
\vdots \\
\psi(N) \psi(N-1) \ldots \psi(1)
\end{array}\right]_{N \times 1},
\end{gathered}
$$

and

$$
b_{3,3}=t_{s}\left[\begin{array}{c}
\zeta(1) \\
\psi(2) \zeta(1)+\zeta(2) \\
\psi(3) \psi(2) \zeta(1)+\psi(3) \zeta(2)+\zeta(3) \\
\vdots \\
\{p \operatorname{si}(N) \psi(N-1) \ldots \psi(2)\} \zeta(1)+\ldots+\psi(N-2) \zeta(N-1)+\zeta(N)
\end{array}\right]_{N \times 1}
$$


while vector $b_{4}(N \times 1)$ becomes,

$$
b_{4}=b_{2,1}-b_{3,2}-b_{3,3} \text {. }
$$

Therefore, matrix $A$ and vector $b$ in canonical form (32) are,

$$
A=\left[\begin{array}{c}
A_{1} \\
-A_{1} \\
A_{2} \\
-A_{2}
\end{array}\right]_{4 N \times 3 N}, \quad b=\left[\begin{array}{l}
b_{1} \\
b_{2} \\
b_{3} \\
b_{4}
\end{array}\right]_{4 N \times 1} .
$$

Finally, the bounds of vector $X$ given in canonical form $(32)$ become,

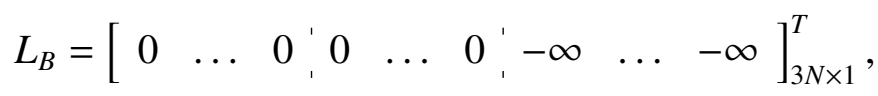

and

$$
U_{B}=\left[\begin{array}{lll:lll:lll}
1 & \ldots & 1 & 1 & \ldots & 1 & \infty & \ldots & \infty
\end{array}\right]_{3 N \times 1}^{T} .
$$

This optimization problem is solved using the SCIP solver in optimization interface (OPTI) toolbox, which is a Matlab toolbox for solving optimization problems.

\section{General data}

\subsection{Case study}

A case of a farm house in Port Elizabeth, South Africa, where an air source HPWH is used to provide hot water, whose temperature is controlled using a thermostat, is considered in this paper. The parameters of this HPWH are shown in Table 1 . In order to satisfy the demand for hot water,

Table 1: Parameters of the HPWH

\begin{tabular}{cccccc}
\hline Power $(k W)$ & COP & Volume $(l)$ & $\Delta \mathrm{x}(\mathrm{m})$ & $\mathrm{k}(W / m K)$ & $\mathrm{h}\left(W / m^{2} K\right)$ \\
\hline 6 & 3.8 & 260 & 0.035 & 0.055 & 6.3 \\
\hline
\end{tabular}

the thermostat has been set at $50{ }^{\circ} \mathrm{C}$. Further, the plumbing pipes for transporting the hot water in the house are 1/2 inch in diameter, with the length of the pipes from the location of the HPWH to the shower being about $25 \mathrm{~m}$. In this study, Stiebel Eltron IS 60E ${ }^{2}$ instantaneous shower, rated at $8.5 \mathrm{~kW}$, is used. Since the shower is the end-use requiring hottest water from the HPWH, the instantaneous shower is set to have the temperature of the hot water such that $47 \leq T_{i s} \leq 50$ while the HPWH can be set at $45 \leq T_{h p} \leq 50$.

The hourly hot water demand for the house was measured, with Figure 2 showing the demand pattern for a period of one day. Further, the occupants provided the information on their showering behaviour in a day, that is, duration in the shower and the average time of the day they take their shower. Using the average flow rate of the low flow shower head already installed in the house, the

$\sqrt[2]{\text { http://www.stiebel-eltron.co.za/is60e.html }}$ 


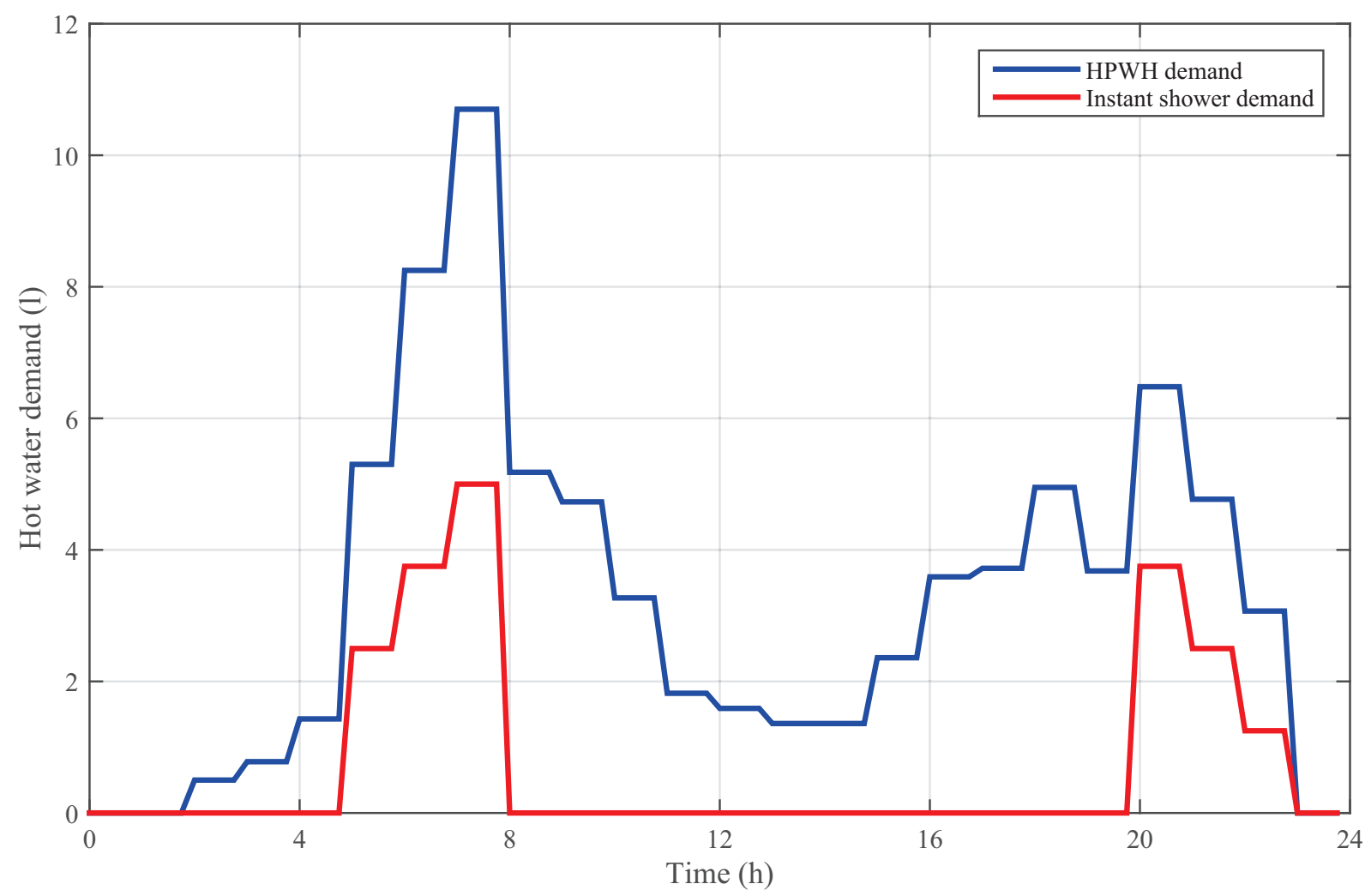

Figure 2: Overall and shower hot water demand pattern.

shower demand in a day was obtained as shown in Figure 2. It can be seen that the demand for hot water is highest in the morning, between 06:00-10:00 which is normally caused by the occupants waking up and preparing to go to work or school. The demand also peaks in the evening hours between 16:00-20:00 caused by the occupants who are back in the house. The demand for hot water in the shower also has a pattern similar to the overall hot water demand.

The hourly temperature variation, together with the ambient temperature for this region was obtained from the Southern African Universities Radiometric Network 3 .

\subsubsection{Renewable energy}

Wind power is part of the input power into this control model. Therefore, a $3.5 \mathrm{~kW}$ Raum wind turbine ${ }^{4}$ is chosen as the wind generator. The turbine has a rated wind speed of $11 \mathrm{~m} / \mathrm{s}$, with the cut-in and cut-out wind speeds being $2.8 \mathrm{~m} / \mathrm{s}$ and $22 \mathrm{~m} / \mathrm{s}$ respectively while the rotor blades have a sweeping area of $12.6 \mathrm{~m}^{2}$. The gearbox and generator efficiency are taken as 0.9 and 0.8 respectively. The average hourly wind speed pattern for a typical day in Port Elizabeth is given by the Southern African Universities Radiometric Network ${ }^{3}$.

Photovoltaic power is also part of the input parameters into the control model, whose parameters are taken from [21].

\footnotetext{
$\sqrt[3]{\text { http: //www. sauran.net/ }}$

4 ww. raumenergy.com
} 


\section{Simulation results and discussion}

This section includes the results of optimal control of hot water devices, optimal consumption of grid power and the effect on the temperature of hot water from both devices. The legend showing peak and off-peak periods of the TOU tariff is the same throughout this paper.

\subsection{Optimal operation of HPWH}

In meeting the overall hot water demand in the house, the HPWH is optimally operated as shown in Figure 3. The optimal controller operates the HPWH during the cheaper off-peak TOU

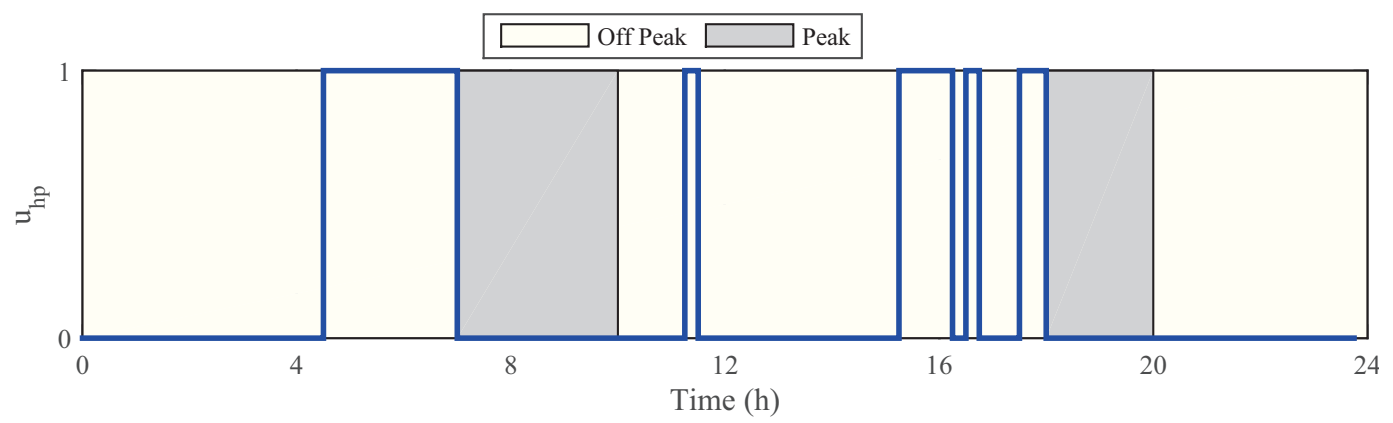

Figure 3: Optimal switching of HPWH.

period hence incurring minimal cost. This load shifting is in line with the country's desire to minimize the load during the peak time so as to improve the quality of the grid. The controller switches on the HPWH at 04:30 on predicting that overall hot water demand is rapidly increasing, until 07:00 to avoid operating during the TOU peak period. The controller thereafter switches on the HPWH at 11:30 for 30 minutes to ensure water temperature is within the required temperature during this period of low hot water demand. As the hot water demand increases in the afternoon going to evening, the HPWH is switched on at 15:15-16:15, 16:30-16:45 and 17:30-18:00, after which it is switched off to avoid the evening TOU peak period. The controller predicts that this hot water will be sufficient to meet the demand for the remaining period of the 24 -h operating cycle.

\subsection{Optimal operation of instantaneous shower}

Figure 4 shows the optimal operation of instantaneous shower. Similar to the HPWH optimal

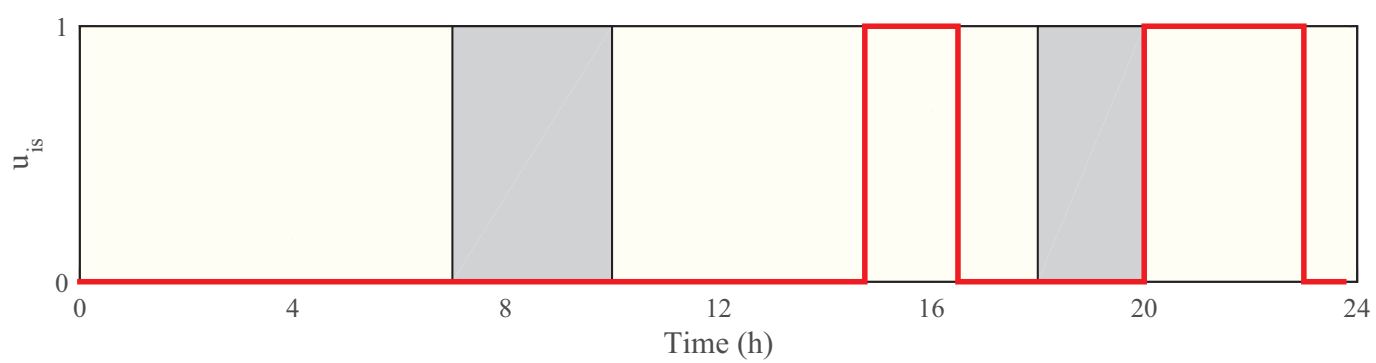

Figure 4: Optimal switching of instantaneous shower. 
operation, the optimal controller also switches the instantaneous shower during the cheaper offpeak periods hence minimizing the cost of electricity while shifting the load. During the morning hours, the controller determines that hot water from HPWH is sufficiently hot to meet the morning hot water demand at the shower. There is therefore no need to switch on the instantaneous shower. However, as the demand from the shower is predicted to rise in the evening, the optimal controller switches on the instantaneous shower on between 14:45-16:30, while switching it off during the evening TOU peak. Thereafter, it is switched on again from 20:00-23:00 when the demand for hot water in the shower ends.

\subsubsection{Optimal grid power consumption}

The consequent optimal power flow in the grid following optimal operation of the hot water devices as well as powering the rest of the domestic load is shown in Figure 5. The grid provides

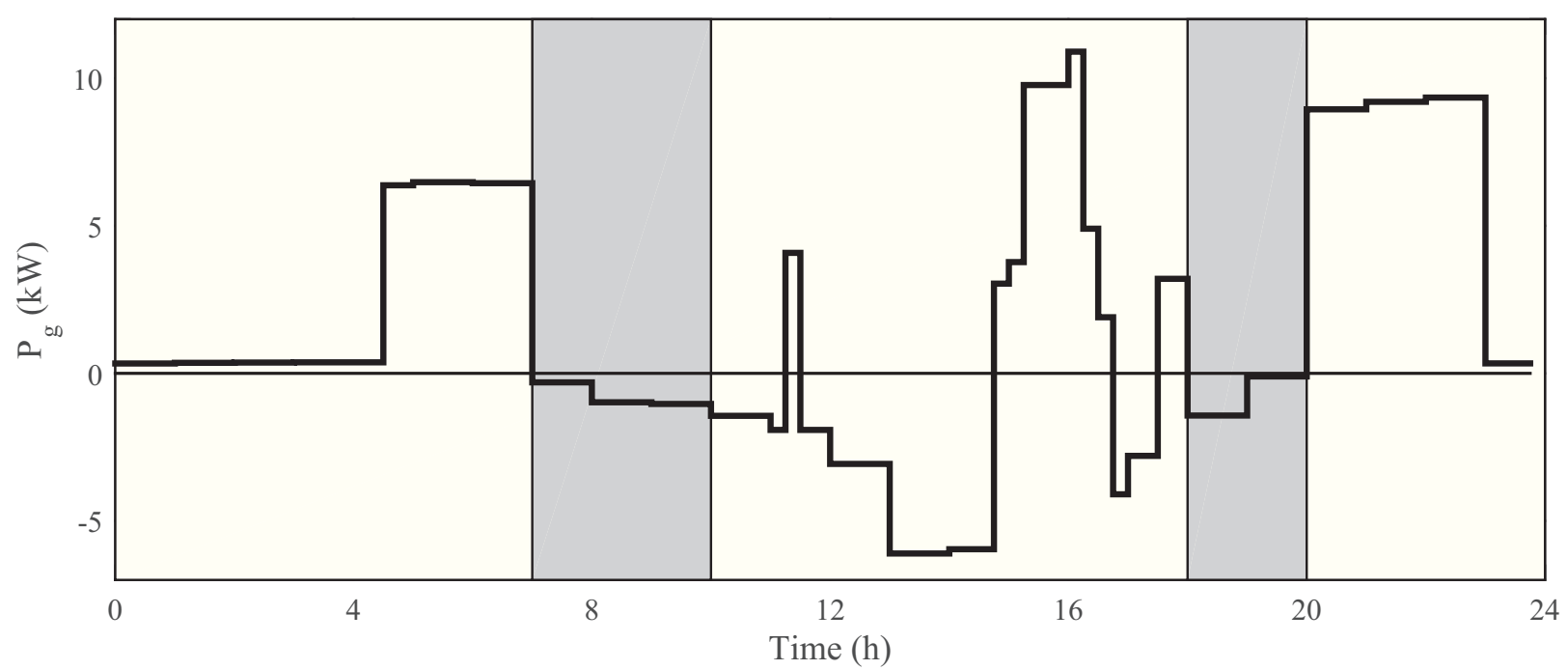

Figure 5: Optimal grid power flow.

minimal power of $0.33 \mathrm{~kW}$ from 00:00-04:30 to cater for the domestic load, in the absence of renewable energy. The operation of the HPWH from 04:30-07:00 increases grid power consumption which reduces after it is switched off. This increase is attributed to the absence of renewable energy during these hours. During the morning TOU peak, both devices are off and the presence of solar power leads to excess power being sold back to the grid. This is actually useful in providing power to other households that need power during the peak TOU period. The amount of excess power to the grid continues until 14:45, except at 11:15 when HPWH was switched on for 15 minutes. Grid power consumption is used to supplement the renewable energy at 14:45-18:00 when both devices are switched on, except at 16:45-17:30 when they are off. Again, during the evening peak, both devices are off and there is excess renewable power which is sold back to the grid. Thereafter, there is a steep decline in renewable energy sources forcing the grid supply most of the energy from 20:00-23:00 when the instantaneous shower is in operation. It is important to 
note that the energy sold to the grid appears sporadic as the control model assumes that there is no energy storage.

\subsubsection{Hot water temperature}

During optimal operation of both HPWH and instantaneous shower, the temperature of water varies as shown in Figure 6 throughout the 24 -h operating cycle. The controller does not violate

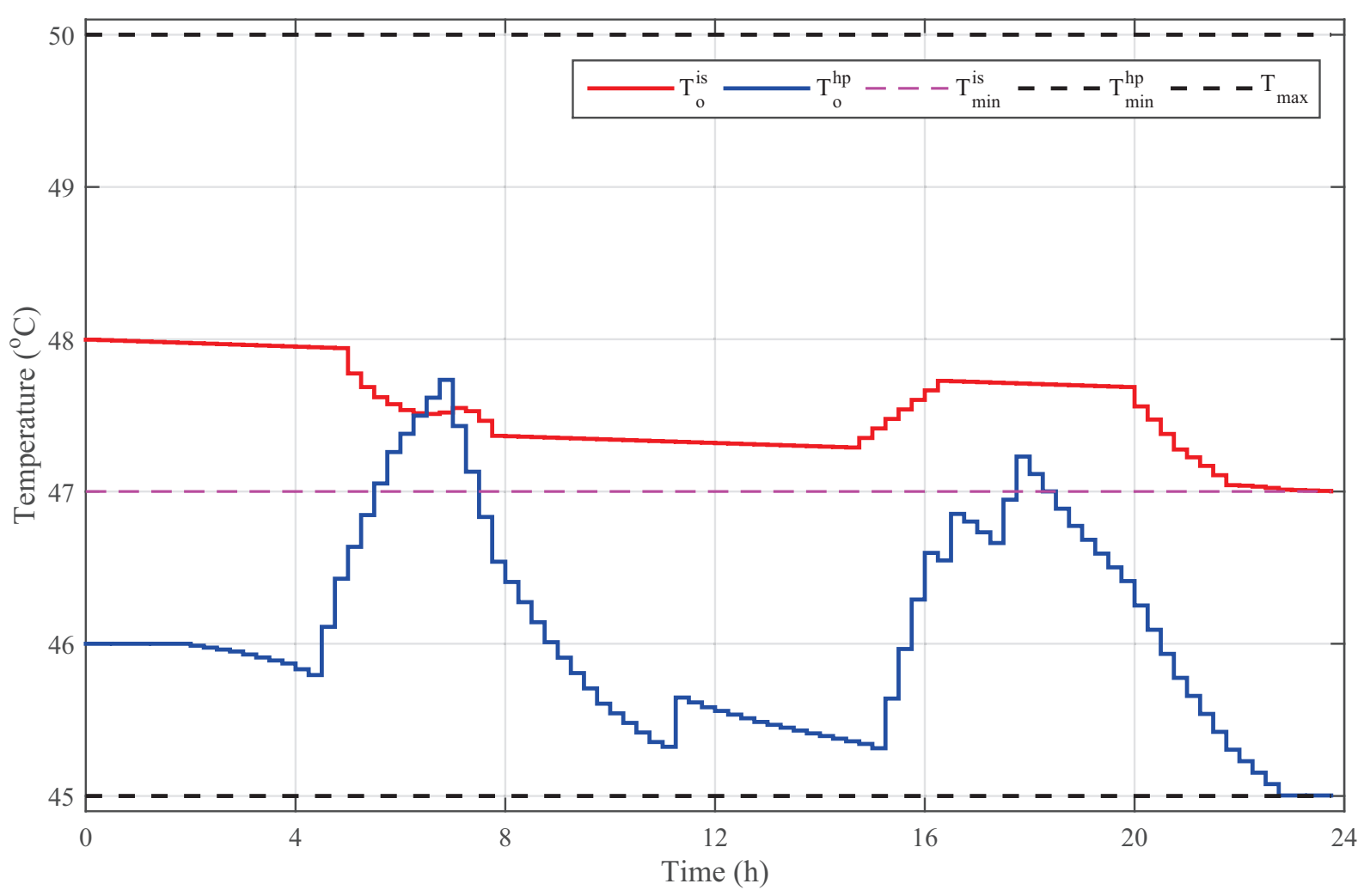

Figure 6: Variation of temperature

any constraints as it meets the required conditions for hot water in the whole house as well as the shower. The temperature of hot water stored in HPWH rises from $46-48.7{ }^{\circ} \mathrm{C}$ between $02: 00-04: 30$ when the controller switches on the HPWH. Thereafter, the temperature starts to fall even though HPWH is on, caused by heat loss as hot water consumption increases. The temperature rises again at 11:00 for 30 minutes and finally between 16:00-18:00 and 20:30-22:00 when HPWH is on.

The temperature of water in instantaneous shower keeps dropping due to standby losses whenever it is idle, like at 00:00-03:30 and 07:30-14:30. However, in its active status, that is, whenever there is demand of hot water in the shower, the temperature variation is caused either by switching on the instantaneous shower if the hot water coming from the HPWH is not sufficiently hot. In the morning, between 04:00-07:00, the rise of temperature of water in the instantaneous shower is caused by the rising temperature of water in the HPWH. There is therefore no need of switching on the instantaneous shower during this period. On the contrary, in the evening shower demand, that 
is, from 20:00-23:00, the temperature of water rises from 15:00 to 18:00. Since the instantaneous shower is off during the evening TOU peak, the temperature keeps falling even when its switched on between 20:00-23:00.

\subsubsection{Power flow}

Figure 7 shows the flow of power in the system throughout the operating cycle whereby, $P_{g, o p t i m a l}$ is the optimal grid power flow resulting from the optimal control strategy. $P_{g, \text { baseline }}$ is

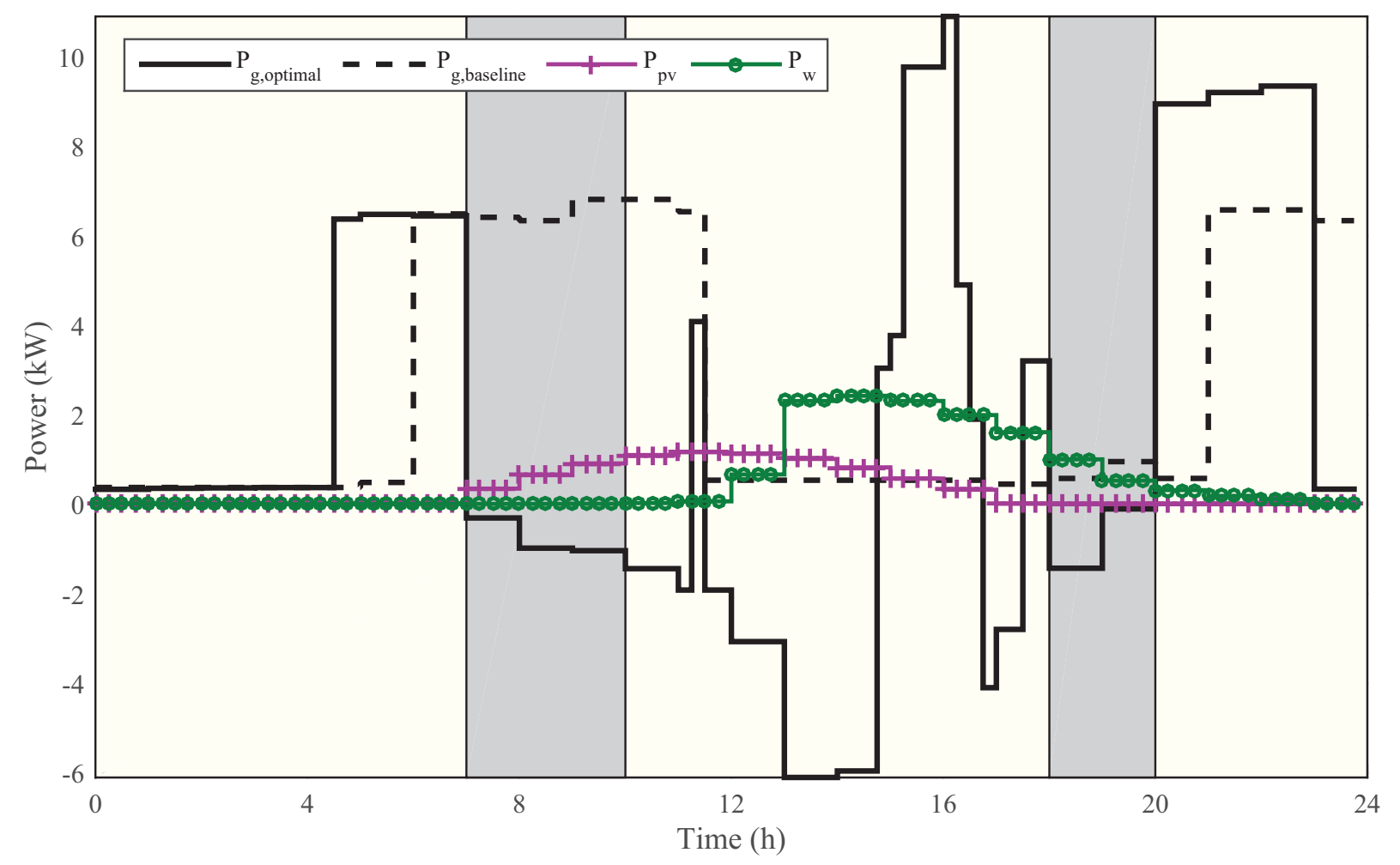

Figure 7: The flow of power during the 24-h horizon

the grid power consumption when the HPWH is controlled by a thermostat and solely powered by the grid in the case study. $P_{p v}$ and $P_{w}$ are the renewable energy generated through PV and wind sources respectively. It can be seen that renewable sources are available during the day, with PV generation beginning at around 07:00 while wind begins at around 12:00, while they end at 17:00 and 23:00 respectively. As the amount of renewable energy increases during the day time, more of it is sold back to the grid (appearing as negative values of $P_{g, \text { optimal }}$ ) whenever the controller switches off both devices. The consumption of power from the grid, $P_{g, \text { optimal }}$, reaches maximum in the evening when both HPWH and instantaneous shower are switched on. This is because the renewable energy being generated in this period is not sufficient to meet the power demand from both devices. The baseline power flow $P_{g, \text { baseline }}$ is operated throughout the morning TOU peak to ensure the water remains hot. This not only leads to higher energy costs being incurred by the end user but it is also against the desire of the power utility to shift load to off-peak periods in order improve the quality of the grid. 


\subsection{Discussion}

Table 2 shows the total daily energy consumption and the savings obtained from use of optimal control strategy with renewable energy sources. The baseline energy is the current scenario in the

Table 2: Daily energy consumption and savings

\begin{tabular}{cccccccc}
\hline \multicolumn{2}{c}{ Baseline } & \multicolumn{2}{c}{ Optimal } & & Feed-in & \multicolumn{2}{c}{ Savings } \\
\cline { 1 - 1 } $\begin{array}{c}\text { Energy } \\
\text { enWhergy }\end{array}$ & Cost & Energy & Cost & & Energy & Cost \\
$(\mathrm{kWh} /$ day $)$ & $(\mathrm{R} /$ day $)$ & $(\mathrm{kWh} /$ day $)$ & $(\mathrm{R} /$ day $)$ & $(\mathrm{kWh} /$ day $)$ & $(\%)$ & $(\%)$ \\
\hline 51.00 & 56.61 & 38.83 & 24.40 & 22.80 & 23.4 & 56.9 \\
\hline
\end{tabular}

case study, where the HPWH is controlled by a digital thermostat and it is powered by grid power alone. It is in addition operated at the temperature range acceptable in the shower, despite the other hot water demands requiring less hot water. Therefore, the baseline cost is the cost incurred by the HPWH under the TOU electricity tariff. The optimal energy is the grid energy consumed upon using optimal controller and renewable energy sources, with the cost obtained from the TOU electricity tariff. The energy and cost savings are obtained from the difference between the baseline and optimal energy consumption and cost respectively. Finally, feed-in energy is the excess solar and wind energy fed back to the grid. In this paper, it is assumed there is no storage and therefore, whenever the renewable energy is excess, it is fed back to the grid through an appropriate feed-in tariff. The optimal controller with both HPWH and instantaneous shower has the potential to save $23.4 \%$ grid energy in a day when compared to the baseline thermostat control of the HPWH. These energy savings occur because of the use of renewable energy as well as operating the HPWH at a slightly lower minimum temperature acceptable in other end uses in the house. The instantaneous shower is used to heat water to higher temperature required in the shower. This control strategy can lead to a cost saving of up to $56.9 \%$ in a day when compared to the baseline thermostat controlled case.

In the case considered, where the length of the $1 / 2$ inch diameter plumbing system from the HPWH storage to the shower is about $25 \mathrm{~m}$, about $3.2 \mathrm{l}$ of water is always stored in these pipes. This water had been heated at one point and remained in the pipes after the previous draw where it cooled off. For a house with four occupants, this translates to about $12.8 l$ if each of them takes just one shower in a day, and up to $19.2 l$ if two occupants shower twice in a day. Therefore, before each shower event in the case study, about $3.2 l$ of water and the associated heating energy is lost as the end-user awaits arrival of hot water. With the use of instantaneous heater, the water stored in the pipe is not wasted as it is heated by the instantaneous shower. Saving this water is important for a dry and developing country like South Africa which is facing water crisis. The results of optimal control of the system incorporating renewable energy systems is in line with similar research [21]. Further, incorporation of instantaneous shower shows the potential in eliminating cold water wastage as hot water is being conveyed to the end-use. Although it is an extra energy consuming device in the house, its efficient operation through optimal control strategy ensures that both energy and water are saved in line with Luo's [26] recommendation.

It has been demonstrated that the combination of HPWH and instantaneous shower powered using renewable energy sources can operate efficiently through the optimal control strategy. This 
leads to energy, water and associated cost savings. Further, through the sale of excess renewable energy back to the grid, the end-users can indeed experience further financial benefits, while also edging closer to achieving near net-zero buildings. If widely adopted, the benefits of this model are important for developing nations as they strive towards energy and water security. The model would go a long way in reducing the greenhouse gas emissions while also improving the quality of grid system available. In remote areas with no grid connectivity, the model can be used with diesel generators being used to supplement renewable energy. However in such a case, an energy storage mechanism should be included.

\section{Conclusion}

The optimal control strategy of both hot water devices has the potential to save energy cost. Further, incorporation of integrated renewable energy sources with optimal control has shown the potential to save energy-not-delivered from the grid, as well as make some money by selling excess energy back to the grid. The inclusion of instantaneous shower allows the HPWH to be operated at a slightly lower temperature hence consuming less energy. It also leads to potential water savings that cools in the pipes and is normally drained as end users wait for hot water to arrive. This control model has the potential to save up to $23.4 \%$ of energy in a day while also avoiding wastage of up to $19 l$ of water in a day. It also has the potential of reducing energy and water bills. The model provides a practical means of integrating of renewable energy sources into homes with the ability of energy trade-off, marking a step closer to zero-energy buildings. This control model is suitable for peri-urban and rural home owners who intend to integrate renewable energy to supply energy-efficient equipment. There is need for further research to incorporate energy storage systems such as batteries and fuel cells. In addition, the control strategy should be advanced to deal with disturbances which are always present in any plant.

\section{Acknowledgements}

The authors would like to thank the National Hub for Energy Efficiency and Demand Side Management (EEDSM) for supporting this research.

\section{References}

[1] S. Lal, A. Raturi, Techno-economic analysis of a hybrid mini-grid system for Fiji islands, International Journal of Energy and Environmental Engineering 3 (1) (2012) 1-10.

[2] D. Weisser, On the economics of electricity consumption in small island developing states: a role for renewable energy technologies?, Energy Policy 32 (1) (2004) 127 - 140.

[3] L. Pérez-Lombard, J. Ortiz, C. Pout, A review on buildings energy consumption information, Energy and buildings 40 (3) (2008) 394-398.

[4] K. van Alphen, M. P. Hekkert, W. G. van Sark, Renewable energy technologies in the Maldives- Realizing the potential, Renewable and Sustainable Energy Reviews 12 (1) (2008) 162 - 180.

[5] H. Tazvinga, B. Zhu, X. Xia, Energy dispatch strategy for a photovoltaic-wind-diesel-battery hybrid power system, Solar Energy 108 (2014) 412-420.

[6] A. Hepbasli, Y. Kalinci, A review of heat pump water heating systems, Renewable and Sustainable Energy Reviews 13 (6) (2009) 1211-1229. 
[7] X. Liu, S.-K. Lau, H. Li, Optimization and analysis of a multi-functional heat pump system with air source and gray water source in heating mode, Energy and Buildings 69 (2014) 1-13.

[8] H. Singh, A. Muetze, P. Eames, Factors influencing the uptake of heat pump technology by the UK domestic sector, Renewable energy 35 (4) (2010) 873-878.

[9] F. Alam, T. Theos, A new generation energy efficient residential house in Australia, in: Proceedings of the 4th BSME-ASME International Conference on Thermal Engineering (ICTE2008), Paper AU-01, 2008, pp. $27-29$.

[10] E. Ghisi, S. Gosch, R. Lamberts, Electricity end-uses in the residential sector of Brazil, Energy Policy 35 (8) (2007) 4107-4120.

[11] A. S. Vieira, R. A. Stewart, C. D. Beal, Air source heat pump water heaters in residential buildings in Australia: Identification of key performance parameters, Energy and buildings 91 (2015) 148-162.

[12] K. Chua, S. Chou, W. Yang, Advances in heat pump systems: A review, Applied Energy 87 (12) (2010) 36113624.

[13] J. Ji, G. Pei, T.-t. Chow, W. He, A. Zhang, J. Dong, H. Yi, Performance of multi-functional domestic heat-pump system, Applied Energy 80 (3) (2005) 307-326.

[14] S. M. Sichilalu, X. Xia, Optimal energy control of grid tied pv-diesel-battery hybrid system powering heat pump water heater, Solar Energy 115 (2015) 243-254.

[15] S. Sichilalu, X. Xia, Optimal power control of grid tied pv-battery-diesel system powering heat pump water heaters, Energy Procedia 75 (2015) 1514-1521.

[16] L. Kreuder, C. Spataru, Assessing demand response with heat pumps for efficient grid operation in smart grids, Sustainable Cities and Society 19 (2015) 136-143.

[17] N. Aste, R. Adhikari, M. Manfren, Cost optimal analysis of heat pump technology adoption in residential reference buildings, Renewable energy 60 (2013) 615-624.

[18] B. Alimohammadisagvand, J. Jokisalo, S. Kilpeläinen, M. Ali, K. Sirén, Cost-optimal thermal energy storage system for a residential building with heat pump heating and demand response control, Applied Energy 174 (2016) 275-287.

[19] S. Sichilalu, X. Xia, J. Zhang, Optimal scheduling strategy for a grid-connected photovoltaic system for heat pump water heaters, Energy Procedia 61 (2014) 1511-1514.

[20] S. M. Sichilalu, X. Xia, Optimal power dispatch of a grid tied-battery-photovoltaic system supplying heat pump water heaters, Energy Conversion and Management 102 (2015) 81-91.

[21] S. Sichilalu, T. Mathaba, X. Xia, Optimal control of a wind-pv-hybrid powered heat pump water heater, Applied Energydoi:http://dx.doi.org/10.1016/j.apenergy.2015.10.072

[22] S. Sichilalu, H. Tazvinga, X. Xia, Optimal control of a fuel cell/wind/pv/grid hybrid system with thermal heat pump load, Solar Energy 135 (2016) 59-69.

[23] D. S. Sowmy, R. T. Prado, Assessment of energy efficiency in electric storage water heaters, Energy and Buildings 40 (12) (2008) 2128-2132.

[24] H. M. Sachs, J. Talbot, N. Kaufman, Emerging hot water technologies and practices for energy efficiency as of 2011, Tech. Rep. A112, American Council for an Energy Efficient Economy (February 2012).

[25] E. M. Wanjiru, X. Xia, Energy-water optimization model incorporating rooftop water harvesting for lawn irrigation, Applied Energy 160 (2015) 521-531.

[26] S. Luo, Achieving water conservation and energy efficiency with electric tankless water heaters, American Water Works Association. Journal 102 (2) (2010) 84.

[27] S. Ashok, Optimised model for community-based hybrid energy system, Renewable energy 32 (7) (2007) 11551164.

[28] H. Li, Z. Chen, H. Polinder, Optimization of multibrid permanent-magnet wind generator systems, IEEE Transactions on Energy Conversion 24 (1) (2009) 82-92.

[29] A. Belkaid, I. Colak, O. Isik, Photovoltaic maximum power point tracking under fast varying of solar radiation, Applied Energy 179 (2016) 523-530.

[30] H. Tazvinga, X. Xia, J. Zhang, Minimum cost solution of photovoltaic-diesel-battery hybrid power systems for remote consumers, Solar Energy 96 (2013) 292-299.

[31] M. Collares-Pereira, A. Rabl, The average distribution of solar radiation-correlations between diffuse and hemispherical and between daily and hourly insolation values, Solar Energy 22 (2) (1979) 155-164. 
[32] E. M. Wanjiru, L. Zhang, X. Xia, Model predictive control strategy of energy-water management in urban households, Applied Energy 179 (2016) 821-831.

[33] D. Setlhaolo, X. Xia, Optimal scheduling of household appliances with a battery storage system and coordination, Energy and Buildings 94 (2015) $61-70$.

[34] A. Pegels, Renewable energy in south africa: Potentials, barriers and options for support, Energy policy 38 (9) (2010) 4945-4954.

[35] R. Rasmussen, J. MacArthur, E. Grald, G. Nowakowski, Performance of engine-driven heat pumps under cycling conditions, ASHRAE Trans.;(United States) 93 (CONF-870620-).

[36] M. Kim, M. S. Kim, J. D. Chung, Transient thermal behavior of a water heater system driven by a heat pump, International journal of refrigeration 27 (4) (2004) 415-421.

[37] A. A. Hegazy, M. Diab, Performance of an improved design for storage-type domestic electrical water-heaters, Applied energy 71 (4) (2002) 287-306.

[38] H. Mehling, L. F. Cabeza, S. Hippeli, S. Hiebler, Pcm-module to improve hot water heat stores with stratification, Renewable Energy 28 (5) (2003) 699-711.

[39] A. U. Atmaca, A. Erek, H. M. Altay, Comparison of two numerical approaches to the domestic hot water circuit in a combi boiler appliance, Energy and Buildings 127 (2016) 1043-1056.

[40] M. Gustafson, J. Baylor, G. Epstein, Direct water heater load control-estimating program effectiveness using an engineering model, IEEE transactions on power systems 8 (1) (1993) 137-143.

[41] A. H. Fanney, R. R. Zarr, J. Ketay-Paprocki, Thermal performance of residential electric water heaters using alternative blowing agents, Transactions- American Society of Heating Refrigerating and Air Conditioning Engineers 106 (2) (2000) 377-394.

[42] P. Kepplinger, G. Huber, J. Petrasch, Field testing of demand side management via autonomous optimal control of a domestic hot water heater, Energy and Buildings 127 (2016) 730-735.

[43] P. Dolan, M. Nehrir, V. Gerez, Development of a monte carlo based aggregate model for residential electric water heater loads, Electric Power Systems Research 36 (1) (1996) 29-35.

[44] R. Milward, Electric tankless water heating: competitive assessment, Tech. Rep. 1285-5-04, Global Energy Partners, LLC (March 2005).

[45] G. P. Henze, D. P. Yuill, A. H. Coward, Development of a model predictive controller for tankless water heaters, HVAC\&R Research 15 (1) (2009) 3-23.

[46] R. K. Johnson, C. A. Clark, Field evaluation of two demand electric water heaters., ASHRAE transactions 112 (1) (2006) 426-435.

[47] G. Johnson, I. Beausoleil-Morrison, The calibration and validation of a model for predicting the performance of gas-fired tankless water heaters in domestic hot water applications, Applied Energy 177 (2016) 740-750.

[48] D. Kosar, J. Stair, Short-term performance of gas-fired tankless water heater: Laboratory characterization, ASHRAE Transactions 119 (2013) 48-69.

[49] S. S. Rao, S. Rao, Engineering optimization: theory and practice, John Wiley \& Sons, 2009.

[50] B. Numbi, J. Zhang, X. Xia, Optimal energy management for a jaw crushing process in deep mines, Energy 68 (2014) $337-348$. 